\title{
The Impact on Implementing Agile Methodology during Pandemic of Covid-19
}

\author{
Effah A. Kadasah and Danah Alabdulmohsin \\ Master Student, King Saud University, Saudi Arabia
}

\begin{abstract}
The Covid-19 pandemic during 2020 and 2021 forced many companies and organizations to directly shift to remote working. The main goal of this research paper is to study the effect of the pandemic restrictions on software engineering teams who have been implementing Agile methodology already or recently adopting it in their projects after the pandemic. The survey was distributed to people who work on software engineering projects to get their feedback about how their work and production got affected by the pandemic. The survey focused on six main areas which are Agile adoption, the impact in Agile manifesto, the delivery of the project, methods and tools used, skills gained and improved, and last area was the challenges and advantages of the pandemic from participants' point of view. We noticed that many software projects during the pandemic period adopt the Agile method, whether they have been utilizing it previously or adopting it recently during the pandemic period, due to its flexibility, adaptability, resilience, and responsiveness. We also found out that software development projects implementing Agile methodology are less affected by the pandemic, based on the participants' answers related to the main value of Agile and delivery of the project.
\end{abstract}

Keywords: Agile software development, Pandemic, Covid-19, Questionnaire, Remote working

\section{Introduction}

In the past year, exactly on 8th of December 2019, the first case of the new coronavirus disease (Covid-19) appeared in Wuhan, China; then in January 2020, the disease began to spread around the world due to direct social communication between one person to another (Nandwani, 2020). With the spread of the virus in most of the countries in the world, the World Health Organization announced a Public Health Emergency of International Concern and many countries' governments announced states of emergency or lockdowns which affect many businesses and enterprises (Ralph et al., 2020).

Mairead, Kieran and Denis stated that due to the covid-19 disease, many of the organizations have been forced to operate the work from home for all or most of their employees (O Connor et al., 2021). Rafael et. al, mentioned that many organizations and companies got affected by the pandemic in many fields especially in the software engineering field that made them change their processes, methods, communication .... etc (Camara et al., 2020). They also mentioned that social distancing during the COVID-19 situation has impacted many companies that are not utilizing any virtual team ways; the impact was on their projects, collaboration of the team 
members and productivity (Camara et al., 2020). Grirish Nandwani stated that the pandemic has reflected the implicit need of the organizations to quickly become Agile which lead them and their partner to work together to enable working remotely for performing all the related operations as well as for increasing the flexibility of the business (Nandwani, 2020).

In recent years, different frameworks under Agile methodology are used worldwide for software development which become very common due to the distribution of Agile teams (Marek et al., 2021). Agile methodologies for software engineering enable companies to handle the issues caused by the pandemic that affect the software projects. While some companies are already applying agile methodologies, some companies are shifting to agility due to COVID19 situation. Our research investigates the impact of COVID-19 on the software engineering projects in many sectors which are applying any framework which is related to agile methodology including Scrum, Kanban, or Extreme programming. We will discuss how the team members with different roles and responsibilities have got affected by the pandemic in their daily tasks or in their project in general.

This paper is organized as follows: section 2 is presenting a background of Agile in software development and Covid-19 pandemic. In section 3, we talk about the related work to implementing Agile in software projects during the pandemic. Section 4 shows the research methodology we used which consists of a description of the questionnaire grouped into 6 main topics, where each topic contains its related questions. In section 5, we present the results of the questionnaire by showing the participants' answers and viewpoints. In section 6, we discuss the results and summarize the main findings. Concluding remarks are given in section 7.

\section{Background}

\subsection{Agile in software development}

According to Jim HighSmith being Agile is the ability to deliver quickly, change quickly, and change often (Zelkowitz, 2004). Over $90 \%$ of the companies are embracing one of the Agile methods for software development (Camara et al., 2020). In software development, Agile establishes the values and behaviors of a project through communication, trust, flexibility, empowerment, and collaboration (Badiale, 2020).

The methodology of Agile is based on developing the software iteratively by a team that is constantly functional and self- organizing with the evolving requirements and solutions (Badiale, 2020). The Agile Manifesto declared the four main values of Agile manifesto to be: emphasizes individuals and interactions over processes and tools, working software over comprehensive documentation, customer collaboration over contract negotiation, and responding to change over following a plan (Sirvastava, 2020). Therefore, the aim of implementing Agile is to expedite the development process by enhancing the communication and collaboration among the team members as well as between the team and the customers, which allows for efficient and effective reactions to any change throughout the project life cycle (Badiale, 2020). Compared with projects implemented with a traditional approach, Agile projects react to changes much faster (Zelkowitz, 2004). 
There are different Agile methods used in software development, and Scrum framework is considered the most widely used Agile method and found successful in many projects (Marek et al., 2021) (Zelkowitz, 2004). Scrum is a rapid process of developing software projects with iterations and increments (Badiale, 2020). Iterations in Scrum are called "sprints" and supported with frequent meetings, such as pre-sprint planning and post-sprint planning meetings, to ensure that all the software development activities are in place (Zelkowitz, 2004).

Another method of Agile in software development and becoming more popular recently is Kanban which was created in 2004 to be used for performing Lean thinking in practice (Ahmad et al., 2013). Kanban's main goal is to lead project teams to concentrate on the workflow and avoid the necessary iterations (Ahmad et al., 2013). This basically happens by visualizing the workflow, reducing the work in progress (WIP) at each phase, and utilizing quicker feedback loops (Ahmad et al., 2013).

In recent times, one of the most common agile methods is Extreme Programming that was formed by Beck, Jeffries, et al. in 1998 (Zelkowitz, 2004). Extreme programming entails 12 rules: the planning game, small releases, system metaphor, simple design, continuous test, refactoring, pair programming, continuous integration, collective code ownership, on-site customer, 40-hour work weeks, and open workspace (Ghani \& Yasin, 2013).

\subsection{Covid-19 Pandemic}

Nowadays, with Covid-19 pandemic most of the world countries are suffering from the global health crisis that led to lockdown which in turn affected many organizations in how they perform their business (Badiale, 2020) (Wahbi et al., 2020). Many challenges came through this lockdown such as employees are required to interact virtually among them as well as with customers and stakeholders (Badiale, 2020). In fact, working remotely during the pandemic is different than working remotely prior to the pandemic for many reasons. First, the restriction of working at home is forced by the governments and has effects on the employees' daily life. Moreover, the schools and daycares were closed which consequently disturb the work life of employees with families (O Connor et al., 2021). Basically, Covid-19 pandemic can be considered as the greatest issue that might confront any organization of any size and in any field (Mykytyn, 2020). In this regard, it could be asked, has Agile software development got impacted by COVID-19?

\section{Related Work}

Since the impact of COVID-19 on Agile software development is a new issue, there is not a significant number of studies in this respect. There was not such a situation that happened to enforce the global industry to work remotely that fast (Marek et al., 2021). Nevertheless, there are several research papers discussing distributed and virtual Agile software development teams.

In the Hawaii International Conference on Software Systems, Jeff Sutherland analyzed the productivity of distributed Agile teams based on a case study. The findings proved that distributed teams could peer the productivity of small collocated teams using excellent realization of Scrum (Sutherland et al., 2007). 
Multiple case studies were done by Maria Paasivaara on Scrum projects to compare the performance between the offsite and the onsite teams. The results were introduced in the Fourth IEEE International Conference on Global Software Engineering, indicating that the projects with distributed teams were superior in transparency and faced fewer communication issues (Paasivaara et al., 2009).

A survey performed by Stanford professor Nicholas Bloom and published in Harvard Business Review, which conducted on a group of Ctrip service representatives sent home to work remotely and compare them with the other employees working in office. The survey had a surprising conclusion that at-home workers were more productive, happier, and less likely to quit (Bloom, 2014).

Victoria Stray analyzed the Slack conversations between two virtual Agile teams located in Norway and Poland to examine the communication and coordination between team members. Based on the case study outcomes, she suggested that to get the advantages of the communication tools, the team members should be familiar with and have clear rules for using these tools (Stray et al., 2019).

A topic of the master's thesis in 2020 was on studying the global virtual software development team using Scrum methodology during COVID-19. M. E. Badiale stated that because of the absence of the office interactions, the pandemic affected the internal communication and hence the team's productivity while the collaboration was not affected (Badiale, 2020). Furthermore, M. E. Badiale pointed out that face to face meetings are crucial to strengthen the relation between team members although technical issues were not a problem for a software development team (Badiale, 2020).

Raišiene conducted a survey on Lithuania's employees' individual characteristics and teleworking during the COVID-19 quarantine period. The research revealed that employees with younger ages and professional experiences in telework were more satisfied with the telework than those older employees who moved to a virtual working environment because of the quarantine (Raišienè et al., 2020).

After analyzing the results of a widely spread questionnaire about working from home during COVID-19 pandemic, Paul Ralph stated that software developers suffered lacking in wellbeing which consequently affected their productivity. Nevertheless, workers who are female, parents, or with disabilities were less affected by the new working situation (Ralph et al., 2020).

Girish Nandwani, a Scrum Master in Natwest Group in India came up with ideas that allow Scrum teams to get effective communications while they work remotely or in distributed locations. Based on the statistical analysis, Nandwani believed that it is the time for companies to adapt to remote working as it has many benefits including flexibility in schedule, working from anywhere, no necessary commuting, and being home with family (Nandwani, 2020). However, the analysis of the statistics pointed out the difficulties that the employees faced while working remotely, which include loneliness, distraction at home, reliable Wi-Fi, and staying motivated (Nandwani, 2020).

Possibilities and challenges of virtual Agile teams in a Nordic organization was discussed by Carita Ristelä. In general, the discoveries of the literature review and the study showed that the 
virtual Agile teams in the researched company had strengths in some areas such as efficiency, flexibility, transparency, and positive attitude from the Scrum master, where some of the obstacles that recognized were developing teams spirit and sharing resources (Ristelä, 2020).

In a recent study to identify the impact of the Covid-19 pandemic and the rapid transition to remote work on the Agile software development team, K. Marek et al. found that the teams did not encounter many troubles in communications and the transition was achieved very smoothly. Most of the surveyed software development teams used metrics, such as Velocity, to check the projects progress and drive decisions (Marek et al., 2021).

\section{4. $\quad$ Research Methodology}

We used a semi-structured survey as a research methodology to gather responses from a specific sample of population. The targeted sample are people who are working or have experience in the field of software development projects using Agile methodology. The questionnaire consists of 26 questions, 2 questions are considered as open-ended questions and 24 questions are considered as close-ended questions. There are 5 general questions which are related to the age, gender, working place (inside Saudi Arabia or outside), sector of the organizations they are working for and the sector of the project they are working on. The other 21 questions are related to the main topic we are examining which is about how implementing Agile methodology during Covid-19 pandemic affects the software projects. The study focuses on the impact of the pandemic on each participant of the survey based on real experiences.

We used a SurveySparrow to build the survey because it is an interesting web tool that can be used easily to create and send surveys to the audience and provides an interesting mobile interface for user experience. The questionnaire was distributed to about 300 persons who experienced the field of software development project using Agile methodology. It was distributed through Linkedin and WhatsApp, and we received around 114 responses, where the number of completed responses were 55 responses. In the analysis of the result we rely only on the completed 55 responses that generate actual results.

The 21 questions which are related to the main topic we examine are classified into 6 main topics: agile adoption, impact on agile manifesto, impact on software development and delivery, tools have been used, improved skills, and challenges and advantages from participants' view of points.

- Topic 1: Agile adoption

Regarding the topic adoption we asked two questions first one was "When have you started implementing Agile methodology in your software development?" to check if they are already implementing agile in their project or they have adopted agile recently after the pandemic occurred. Second question was about the framework they are following under agile in order to discover which framework is mostly used. Third question was regarding their role in the project, if they are: project or product managers, backend/frontend developer, business or system analyst, and software tester.

- Topic 2: Impact on Agile manifesto

We generated the participants' feedback about each one of the four manifesto points. Regarding the "Individuals and interactions over processes and tools" we asked this question "Have the 
interactions between your team members got affected negatively during the pandemic?". For the point of "Working software over comprehensive tools" we asked this question "Has the working software the releasable features of the software got affected negatively during the pandemic?". About the point of "Customer collaboration over contract negotiation" we asked this question "Has the customer involvement in any phase of the software development got affected negatively during the pandemic?". For the last point which is "Responding to change over following a plan" we asked this question "Has the software development responding to change (customer's changes) got affected negatively during the pandemic?".

- Topic 3: Impact on delivery of the software

We generated the participants' feedback about the progress of the project and how the pandemic impacted the delivery of the software. First question was to understand if the team was self-organized to deliver what is needed, we asked this question "Have you and your team members been a self-organizing team during the pandemic?". Second question was to understand if the participants got affected with the lack of a supportive environment for software development, where the question was "Have you and your team members got a supportive and motivational environment for the software development working during the pandemic?". Third question was related to the impact on the continuous delivery of the software features and services by asking this question "Has your team maintained continuous delivery of the developing software during the pandemic?". Fourth question was related to the support and reviewing of each other's work and comment to do enhancement by asking this question "Have you and your team members been able to reflect on each other about the work to improve and make any adjustment during the pandemic?". Fifth question was about how the process of gathering the requirements from the customer or stakeholders got affected by asking this question "Have you and your team members faced any difficulties in gathering requirements from stakeholders during the pandemic?". Sixth question was about the impact on the deployment of the software by asking this question "Have you and your team members faced any difficulties in the deployment of the code during the pandemic?". Seventh question was related to how the pandemic impacted the quality of the software being developed by asking this question "Has the pandemic impacted the quality of the software you are developing?". The last question related to the delivery of the software was about the impact on the UAT (user acceptance testing) by asking this question "What percentage has the pandemic affected the facilitating of the UAT (user acceptance test) negatively?".

- Topic 4: Methods and tools have been used

We generated the participants feedback about the methods and tools they are using during the pandemic and support them for the communication, management of their work and deployment of the software. First question was regarding the communication methods or tools used to communicate with the customer by asking "How do you and your team communicate with the customer during the pandemic?". Second question was related to the methods or tools used to communicate among team members by asking this question "How do you and your team communicate with each other and manage meetings during the pandemic?". Third question was related to the tools used to manage the work including the management of releases and software versions by asking this question "What tools do you use for managing releases and software versions during the pandemic?". Fourth question was about the tools they are using to do 
deployment by asking this question "What tools do you use for software deployment during the pandemic?".

- Topic 5: Skills improved and gained

Here we asked a question about the skills that the participants have improved during the pandemic by asking this question "From your experience with implementing Agile methodologies during the pandemic you've learned more about:" and provide a list of skills to choose from including: being self-organized, being more focused, being responsible, commitment to achieve the goal, openness to new challenge to achieve the goals, having a courage to work on tough problems, responding to change, communicate more with the team, managing the time, and exploring new tools for work.

- Topic 6: Challenges and advantages from participants' points of view

Here we asked two open questions to get their feedback about the challenges they have faced during the pandemic as well as the advantages based on their experience. First question was regarding the difficulties and challenges they have faced by asking this question "State any difficulties or challenges you or any of your team members have encountered at any stage of the software development during the pandemic?". Second question was about the advantages they have got "State any advantages of working Agile online in software development during the pandemic?".

\section{Result}

We got a total of 114 responses, but they dropped to be 55 responses due to the incomplete answers for the survey. In this section we will present the results of the survey starting by general information about the participants then their answers regarding the 6 main topics.

\subsection{General information about participants}

The responses based on the gender resulted as following: (46.81\%) from Male and $(53.19 \%)$ from Female shown in Fig. 1.

Figure 1: Gender of participants

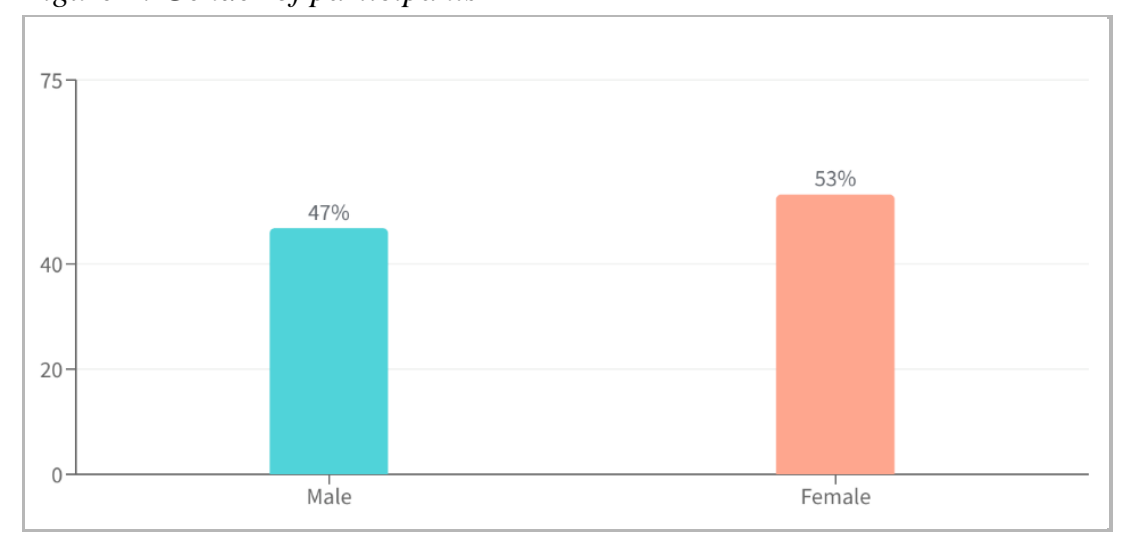

The age of participants divided into 4 groups (20 to 29,30 to 39,40 to 49,50 and more), as shown in Fig. 2 the most responses are from the group of age between 20 to 29 years old which represent the $(64 \%)$ of total responses, then group of age between 30 to 39 years old which 


\section{icmets}

$4^{\text {th }}$ International Conference on Modern Research in

ENGINEERING, TECHNOLOGY AND SCIENCE

AMSTERDAM, NETHERLANDS

$16-18$ July 2021

represent $(35 \%)$ of the responses and finally $(2 \%)$ from the participant that their age is more than 40 years old. For 50 and more years old we got no completed response.

Figure 2: Age of participant

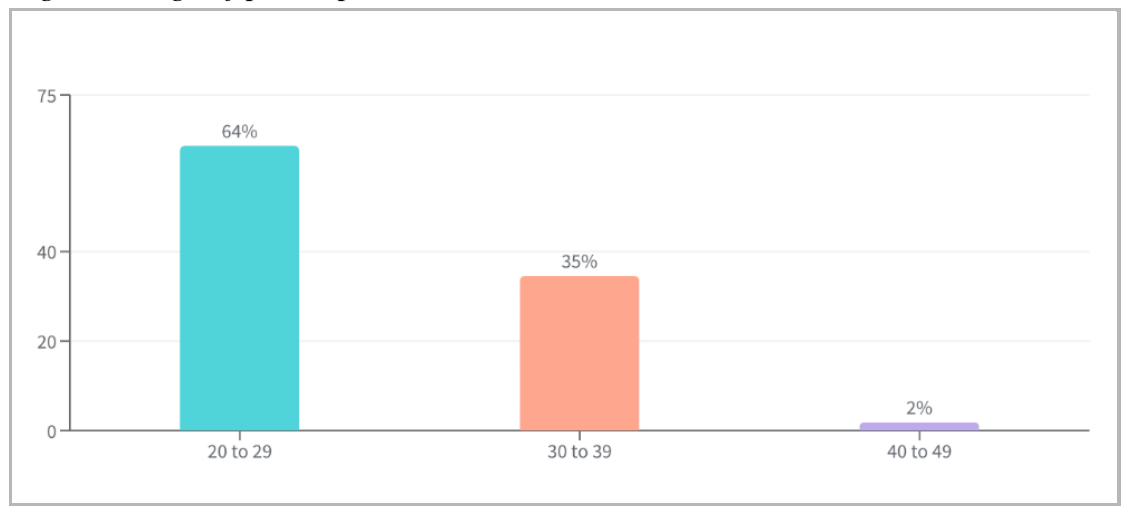

The question regarding their origin of working inside Saudi Arabia or outside, $(96 \%)$ of the responses are inside Saudi Arabia and about (4\%) of responses from other countries as shown in Fig. 3, the participants outside Saudi Arabia are 1 from India and 1 from Kuwait.

Figure 3: Inside or Outside Saudi Arabia

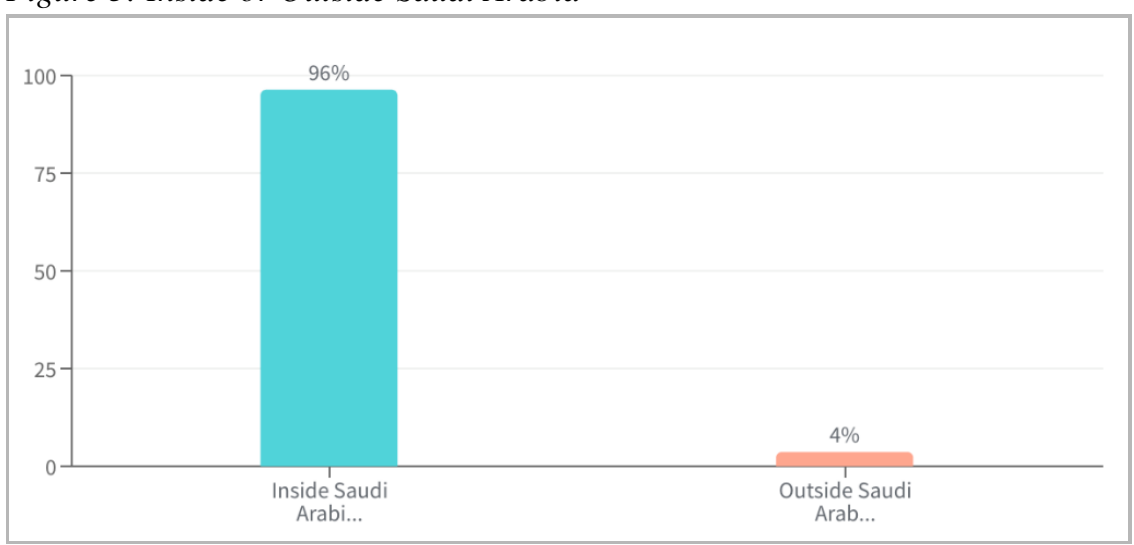

Regarding the sector of the companies that the participants are working for, Fig. 4 shows that most of the participants (67\%) are working in Information Technology Services Companies and the rest are in several sectors.

Figure 4: Company's Sector for Participants 


\section{icmets}

$4^{\text {th }}$ International Conference on Modern Research in

ENGINEERING, TECHNOLOGY AND SCIENCE

AMSTERDAM, NETHERLANDS

$16-18$ July 2021

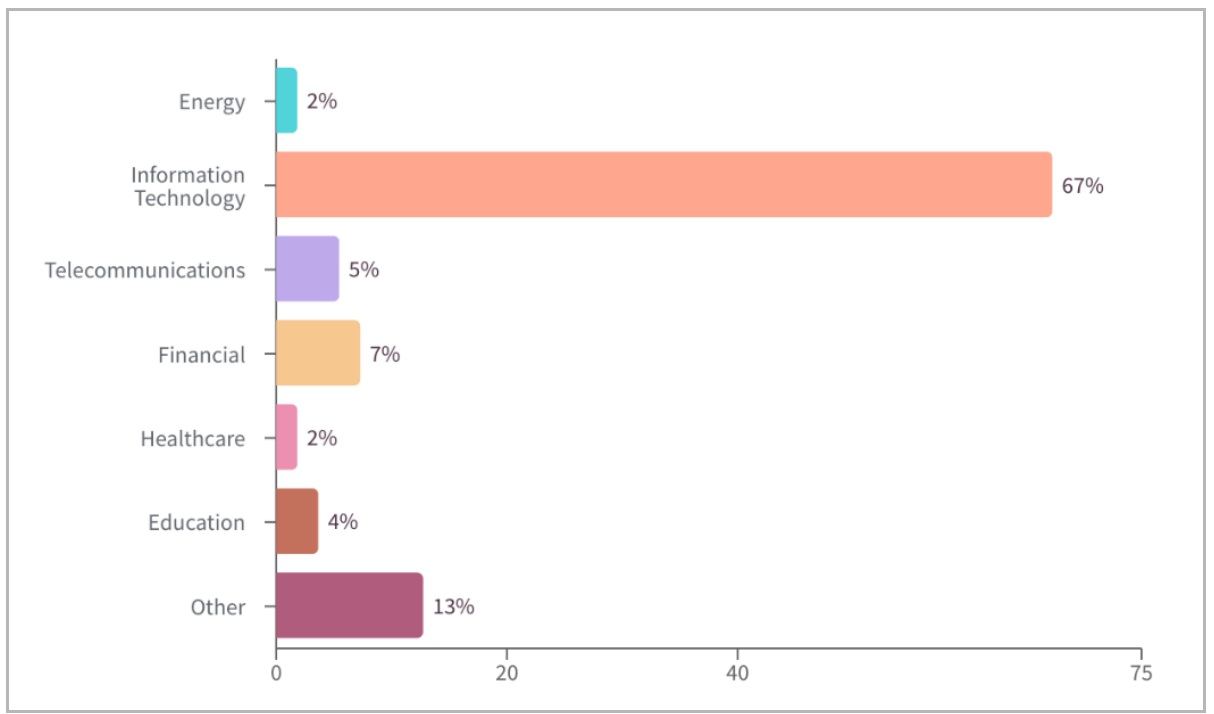

Most of the participants are working on the project for governments with (33\%) of total responses and (31\%) are working on projects for IT services and the rest varies in different sectors as shown in Fig. 5.

Figure 5: Project's Sector of Participants

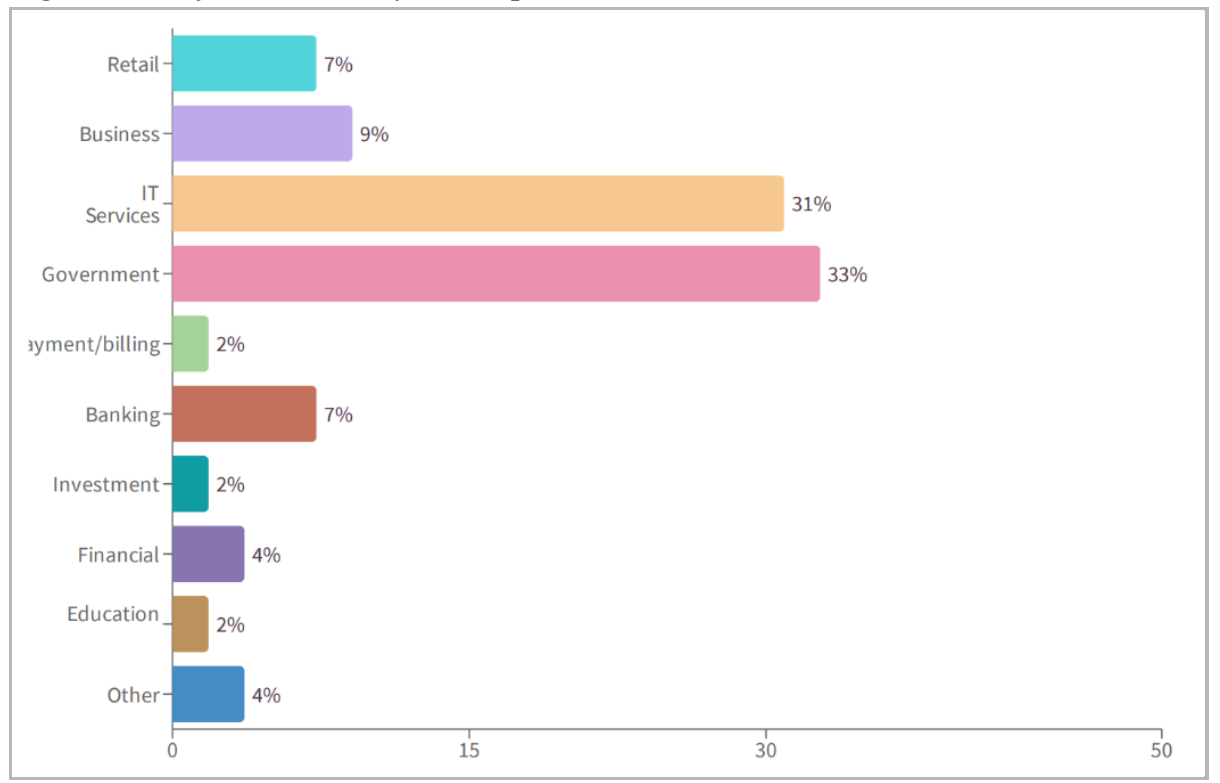

\subsection{Topic 1: Agile Adoption}

Regarding the implementation of agile methodology by using any of its related framework it shows that $(92 \%)$ of the participants have already implementing Agile in their projects and still implementing it during the pandemic where (8\%) have applied agile recently because of the pandemic as shown in Fig. 6. 


\section{icmets}

$4^{\text {th }}$ International Conference on Modern Research in

ENGINEERING, TECHNOLOGY AND SCIENCE

AMSTERDAM, NETHERLANDS

$16-18$ July 2021

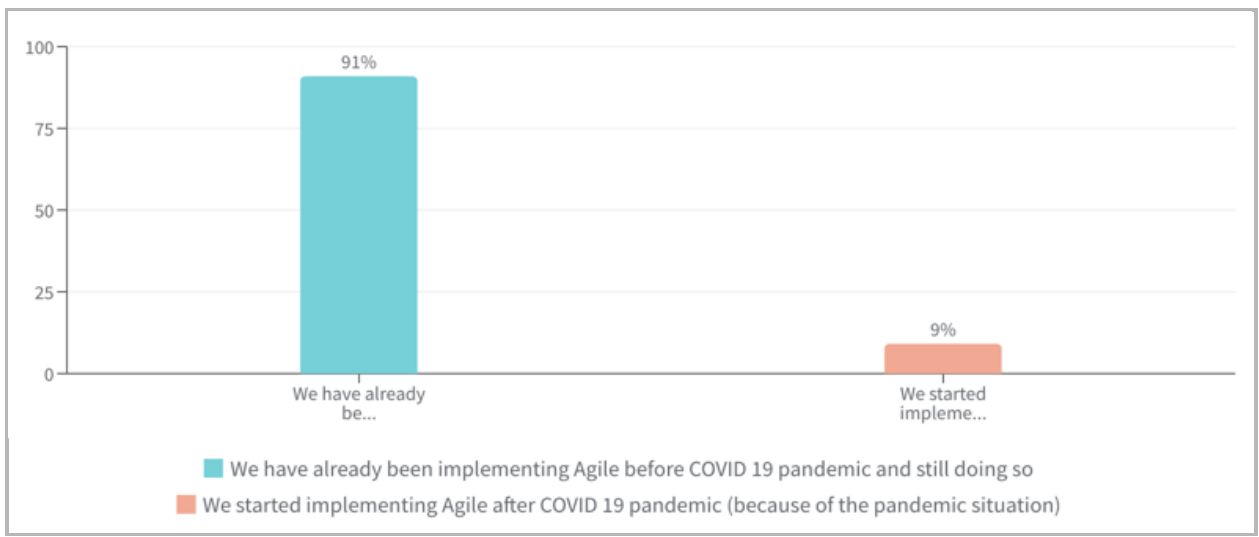

For the Framework, most of the participants are using Scrum framework on their projects by (76\%) of total responses. About (11\%) of participants are using Kanban framework and (9\%) are using Extreme programming framework as shown in Fig. 7.

Figure 7: Agile Framework

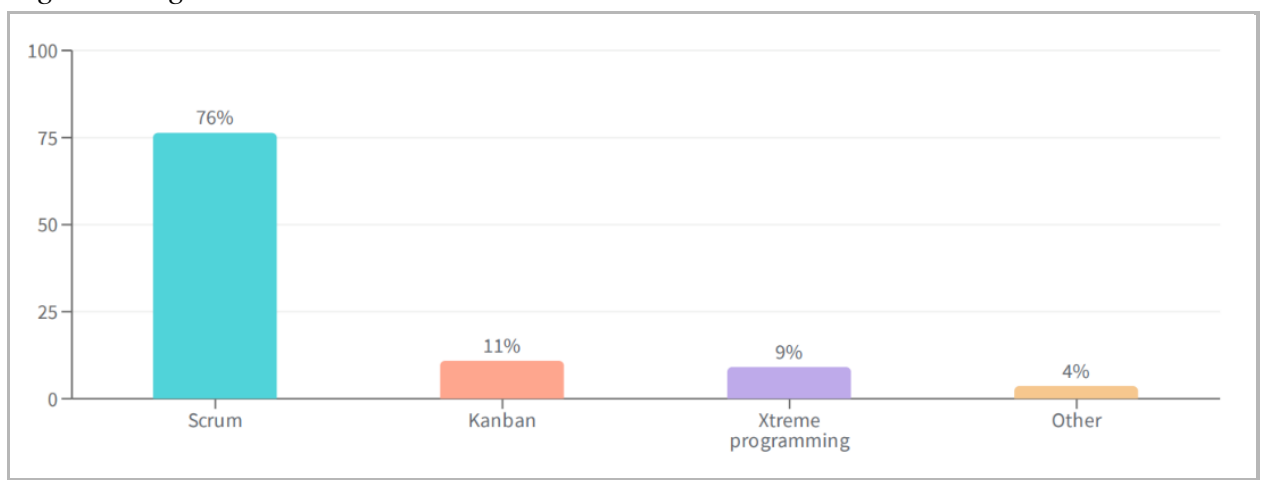

The roles of participants vary as shown in Fig. 8 that (35\%) of participants are working as a developer (back-end or front-end), (31\%) of participants their role is system or business analyst, $(20 \%)$ of participants are project or product managers, and (15\%) are working as software testers (QA).

Figure 8: Roles of Participants

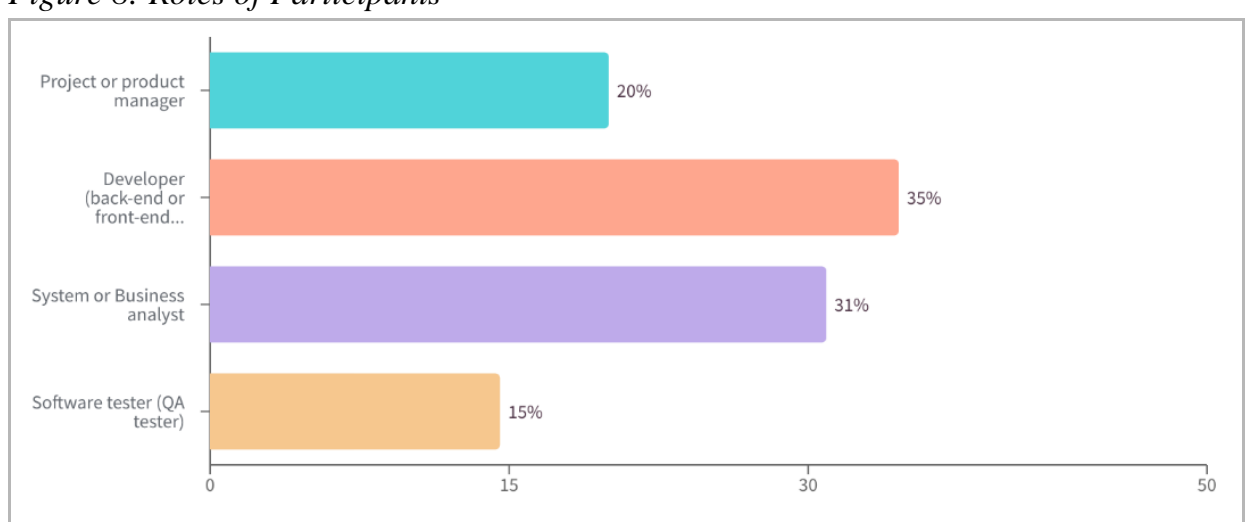




\subsection{Topic 2: Impact on Agile manifesto}

Regarding the participants' feedback about if their interaction with their team members got affected negatively during the pandemic, most of them (60\%) said "No, not at all", where about $(31 \%)$ said that they got affected somehow, and (9\%) said "Yes" as shown in Fig. 9.

Figure 9: If the pandemic negatively affects the interaction among team members or not

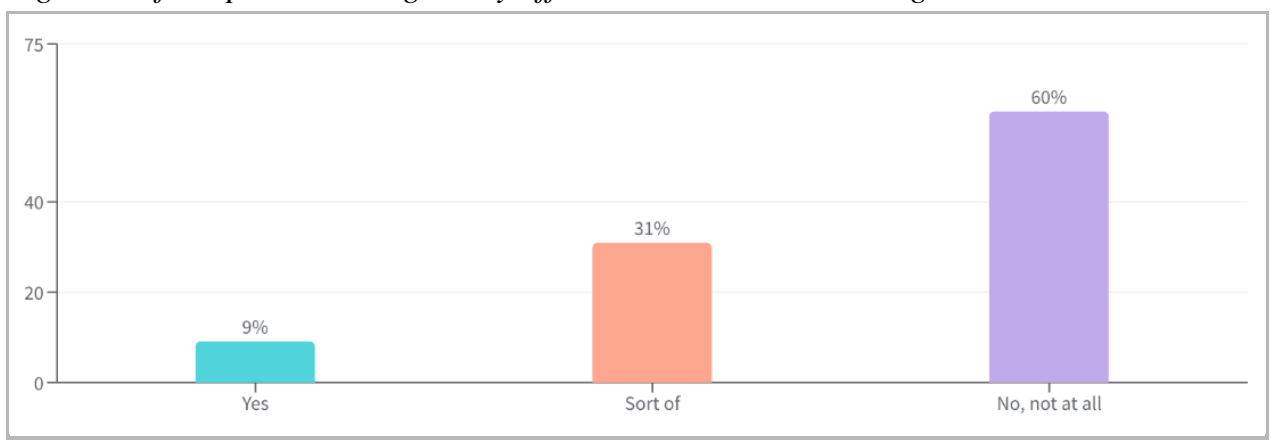

Regarding the participants' feedback about if their goal of delivering a working software features got affected negatively during the pandemic, most of them which is about (51\%) said "No, not at all", about (33\%) of participants said that somehow got affected, and (16\%) of responses said "Yes" got affected as shown in Fig. 10.

Figure 10: If the pandemic negatively affects working software or not

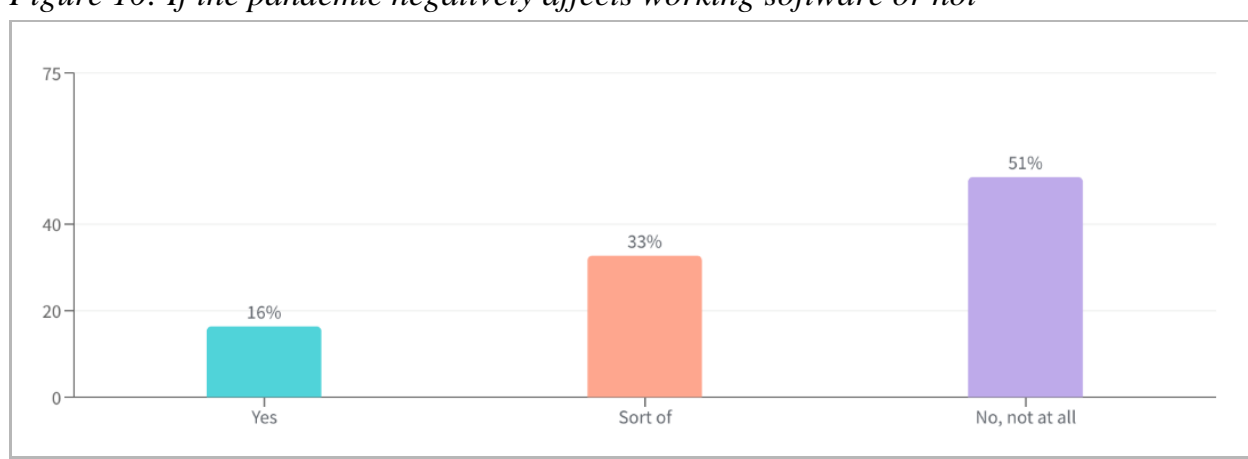

Regarding the participants' feedback about if the collaboration with the customer got affected negatively during the pandemic or not, most of them which is about $(41 \%)$ said "No, not at all", about (36\%) of participants said that somehow got affected, and $(22 \%)$ of responses said "Yes" got affected as shown in Fig. 11.

Figure 11: If the pandemic negatively affects the collaboration with customers or not 


\section{icmets}

$4^{\text {th }}$ International Conference on Modern Research in

ENGINEERING, TECHNOLOGY AND SCIENCE

AMSTERDAM, NETHERLANDS

$16-18$ July 2021

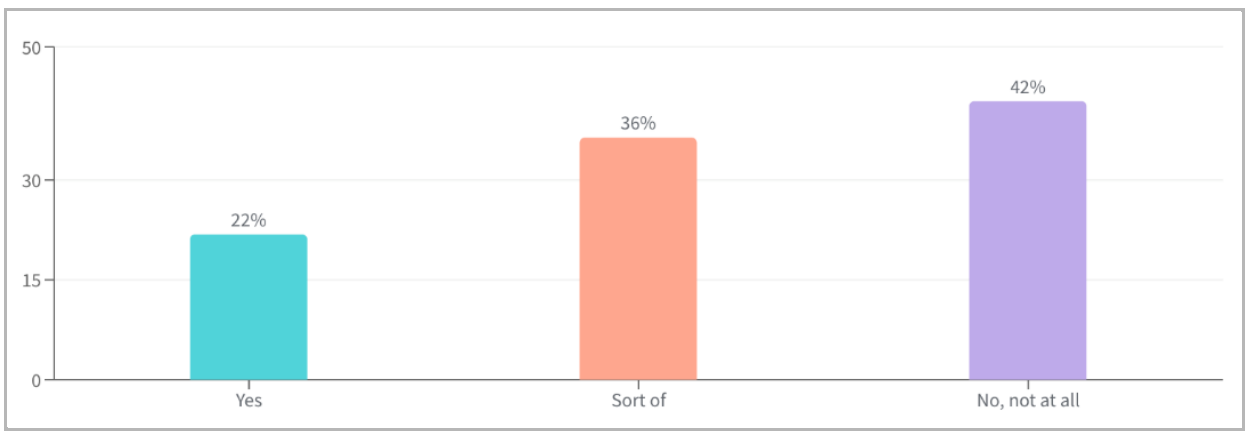

As shown in Fig. 12 regarding the participants' feedback about if the process to respond to change on software development got affected negatively during the pandemic or not, most of them which is about (47\%) said "No, not at all", about (31\%) of participants said that somehow got affected, and (22\%) of responses said "Yes".

Figure 12: If the pandemic negatively affects the responding to change or not

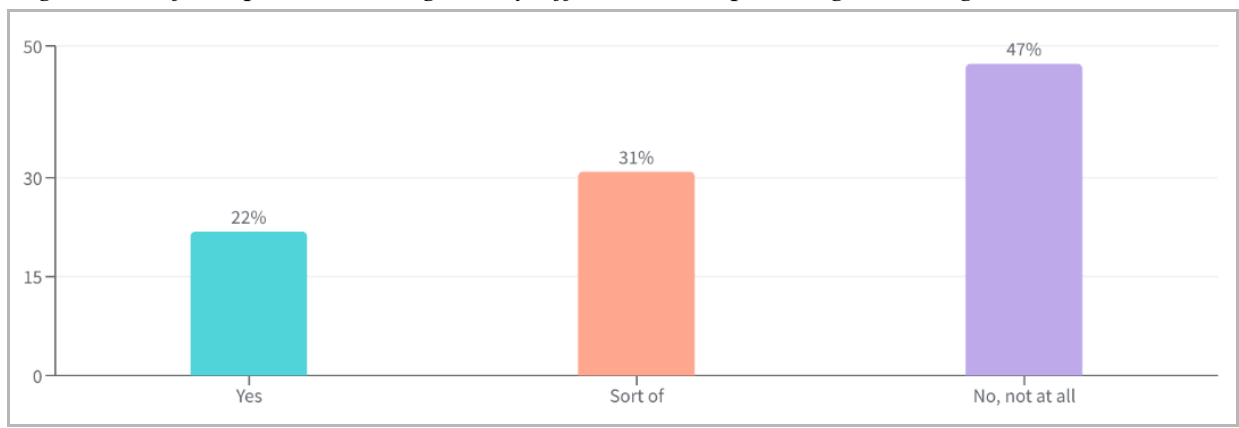

\subsection{Topic 3: Impact on delivery of the software}

Regarding the participants' feedback about being self-organizing teams during the pandemic, about (58\%) said "Yes, all members" are self-organizing team, (36\%) said "Yes, some of team members", and about (5\%) said "No, no one could" as shown in Fig. 13.

Figure 13: If team members were self-organizing team or not

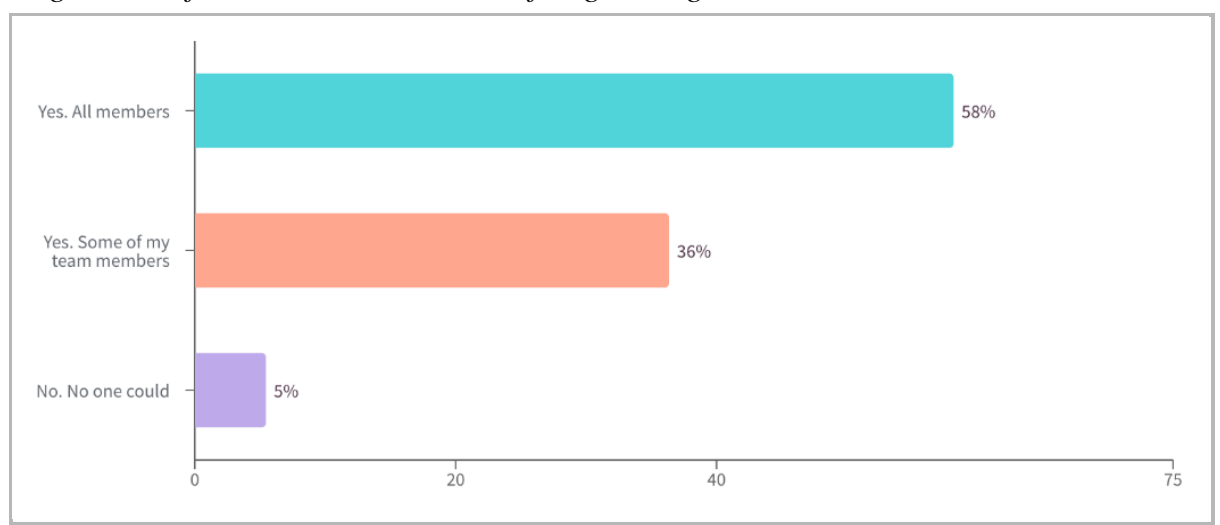


As shown in Fig. 14 regarding the participants' feedback about if they got a supportive and motivational environment for software developing, most of them which is about (60\%) said "yes", about (33\%) of participants said, "sort of" got affected, and (7\%) of responses said "no, not all".

Figure 14: If participants got a supportive and motivational environment for software developing or not

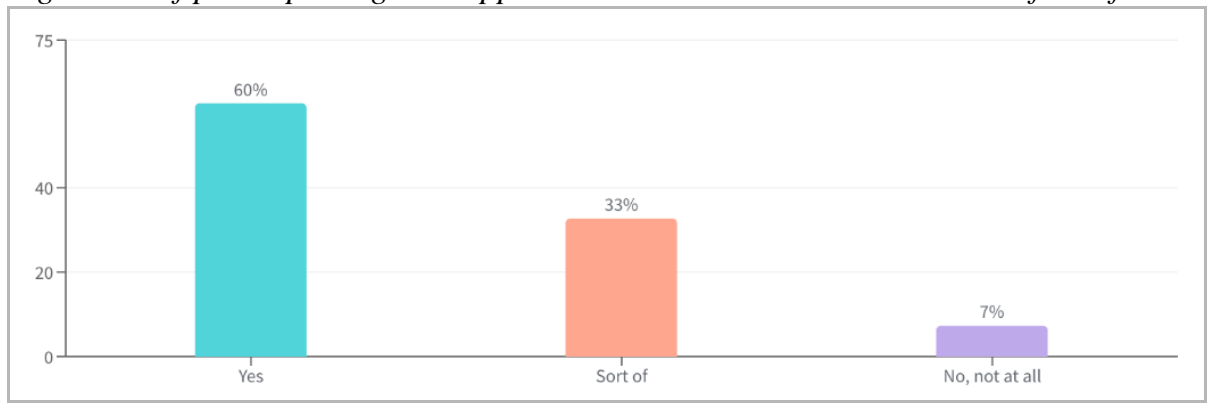

Regarding the participants' feedback about applying a continuous delivery of the software features and services during pandemic, about $(76 \%)$ said "yes" they are providing a continuous delivering of features and services, (9\%) said "No, not at all", and about (15\%) said "Sort of" as shown in Fig. 15.

Figure 15: If participants are applying continuous delivery of software features or not

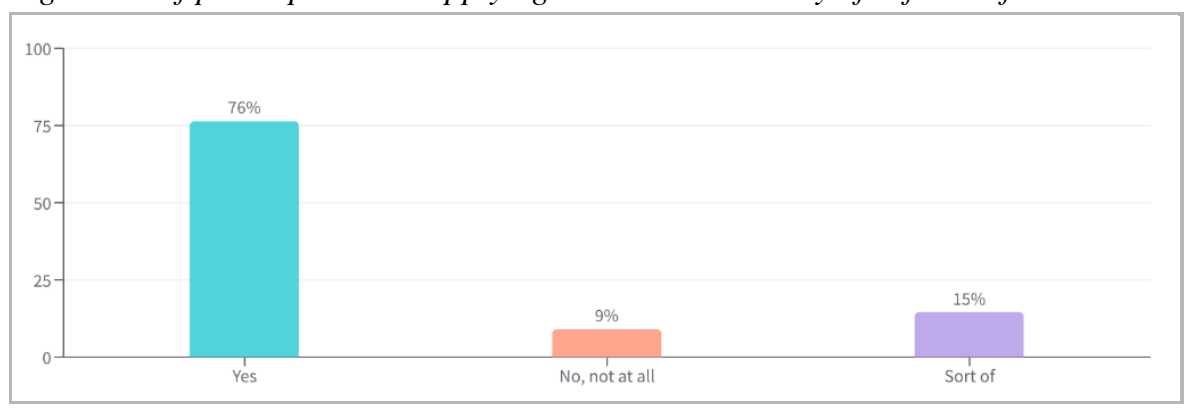

The participants' feedback regarding the ability to reflect on each other work to improve and add adjustment, about (67\%) said "Yes" they are reflecting on each other and make improvement, (18\%) said "No, not at all", and about (15\%) said "Sort of" as shown in Fig. 16.

Figure 16: If participants are reflecting to each other 


\section{icmets}

$4^{\text {th }}$ International Conference on Modern Research in

ENGINEERING, TECHNOLOGY AND SCIENCE
AMSTERDAM, NETHERLANDS

$16-18$ July 2021

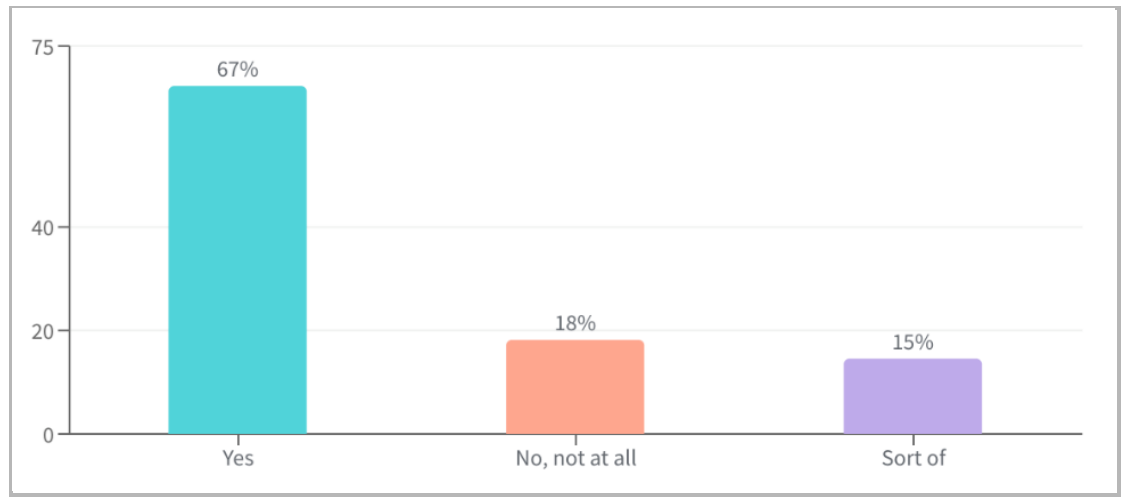

As shown in Fig. 17 the participants' feedback about if they are facing difficulties in gathering the requirements from the customer, most of them which is about (45\%) said "No, not at all", about $(27 \%)$ of participants said "Yes" they are facing difficulties, and (27\%) of responses said, "Sort of".

Figure 17: If participants are facing difficulties in gathering the requirements from customer

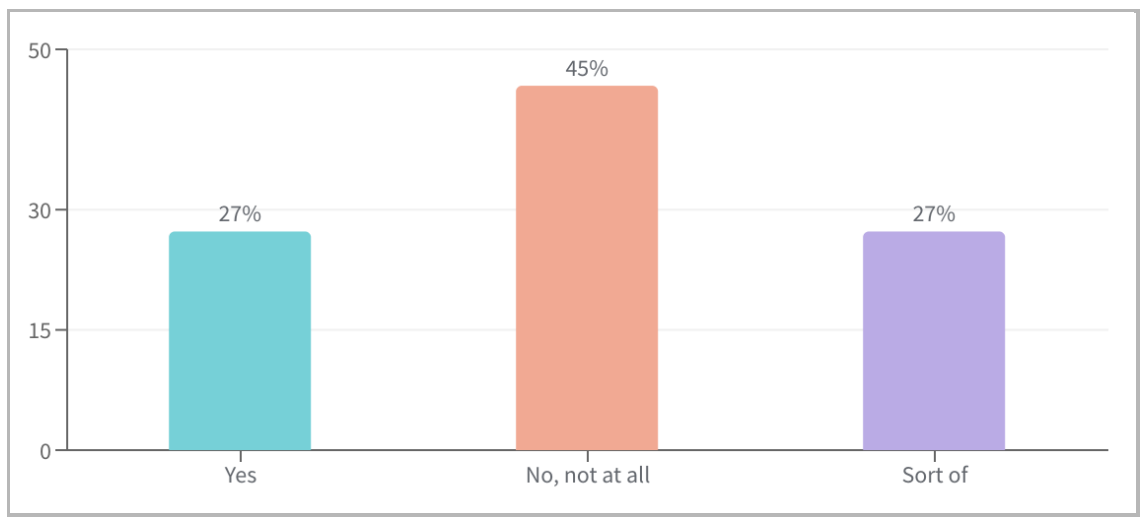

Regarding the participants' feedback if they are facing any difficulties in the deployment of the code during the pandemic, about (58\%) said "No, not at all", (18\%) said "Yes" they are facing difficulties, and about (24\%) said "Sort of" as shown in Fig. 18.

Figure 18: If participants are facing difficulties in the deployment of the code

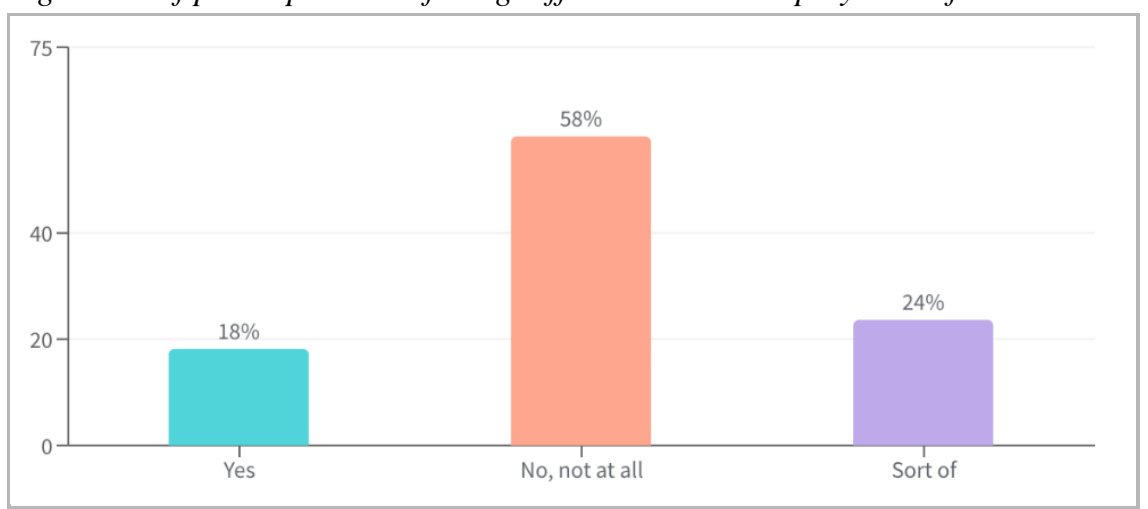


The participants' feedback about if the pandemic impacted the quality of the software, about (49\%) said "No, not at all" which means no impact on software quality, (20\%) said "Yes, a slight negative impact", about (13\%) said "Yes, a slight positive impact", about (11\%) said "Yes, a slight moderate impact", about (2\%) said "Yes, a huge positive impact", and around (5\%) said "Yes, a moderate negative impact" as shown in Fig. 19.

Figure 19: If the quality of the software got affected by pandemic

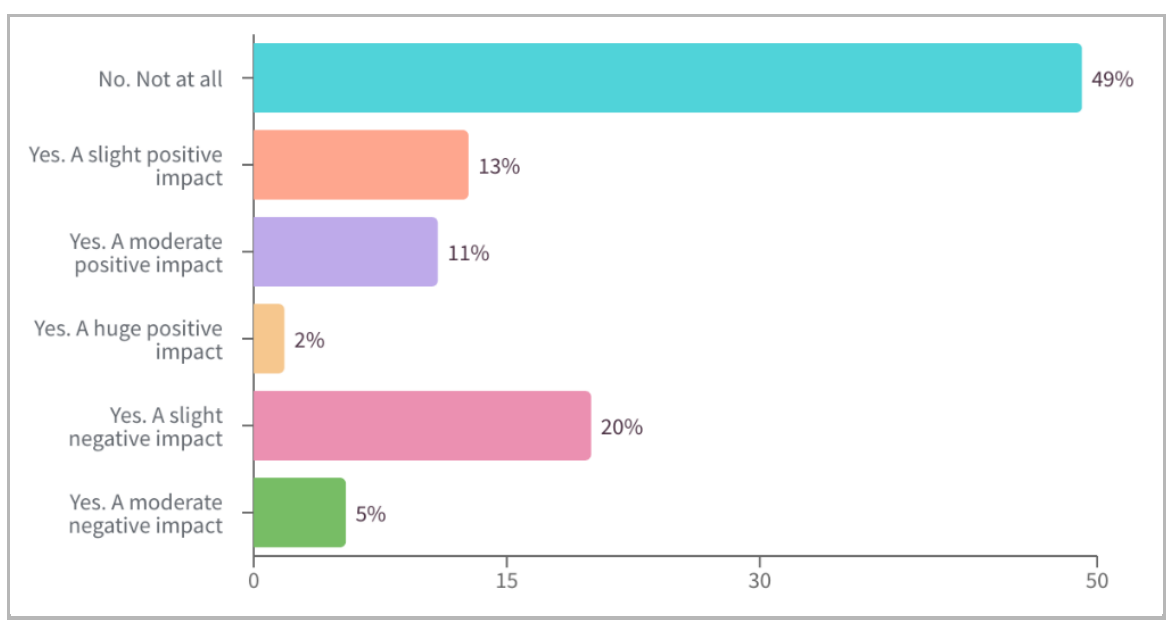

As shown in Fig. 20 regarding the participants' feedback about the percentage of how much the UAT (user acceptance testing) got affected by the pandemic, most of them which is about $(40 \%)$ said that the impact was around " $25 \%$ ", about (29\%) of participants said " 0 " impact on UAT, about (24\%) said about "50\%" impact on the UAT, about (75\%) said the impact was around " $75 \%$ ", and about (2\%) of participants said that the impact was around " $100 \%$ " on the UAT.

Figure 20: The percentage of how much the UAT got affected by pandemic

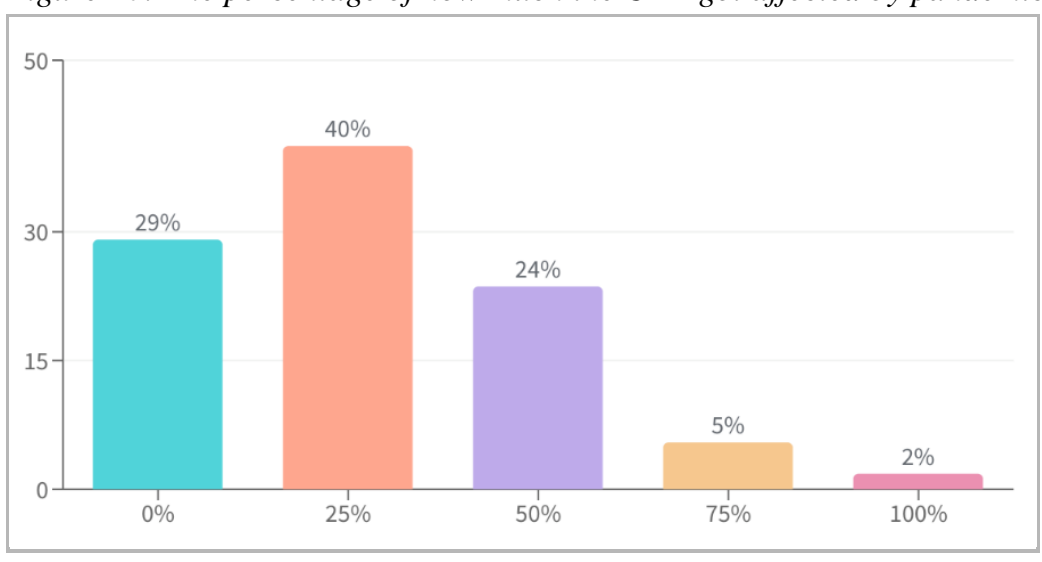

\subsection{Topic 4: Impact on delivery of the software}

Regarding to the participants' feedback about the communication methods or tools that they are using to communicate with customers, around (26\%) are using Microsoft teams, around 
(23\%) are using emails, (20\%) are using the phone calls, (19\%) are using Zoom and (12\%) are using another methods or tools as shown in Fig. 21.

Figure 21: Methods and tools used for communicating with customers

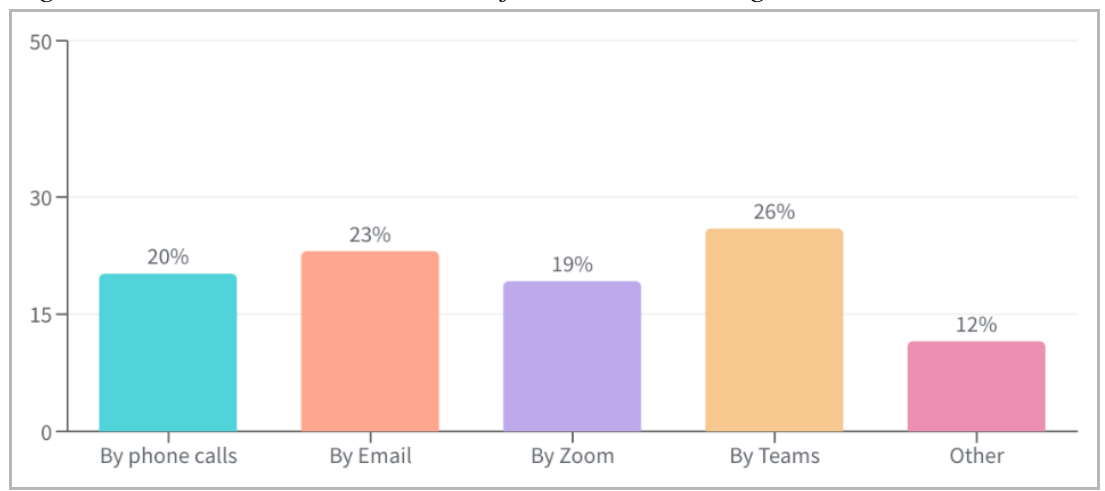

For the participants' feedback about the communication methods or tools that they are using to communicate with their team members, around (20\%) are using Microsoft teams, around (23\%) are using emails, (21\%) are using the phone calls, (18\%) are using Zoom, (9\%) are using Slack, and $(8 \%)$ are using other methods as shown in Fig. 22.

Figure 22: Methods and tools used for team members communication

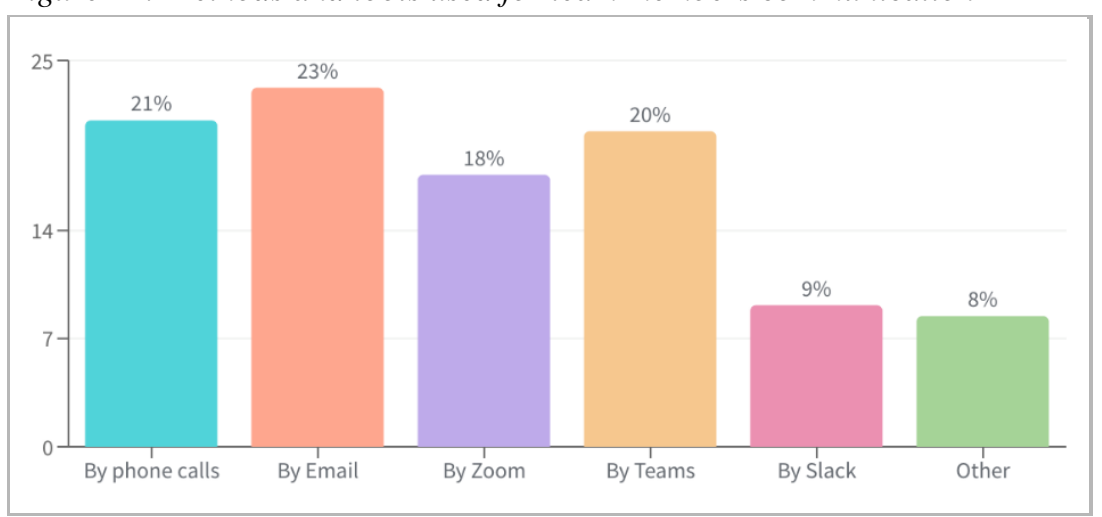

As shown in Fig. 23 regarding the participants' feedback about the tools they are using to manage their work including the management of releases and versions of the software, around (53\%) said they're using Jira, (20\%) said they're using AzureDevOps, around (7\%) said they're using Ansible, (2\%) said they're using Jama, and (18\%) said other tools.

Figure 23: Tools used for software management 


\section{icmets}

$4^{\text {th }}$ International Conference on Modern Research in

ENGINEERING, TECHNOLOGY AND SCIENCE

AMSTERDAM, NETHERLANDS

$16-18$ July 2021

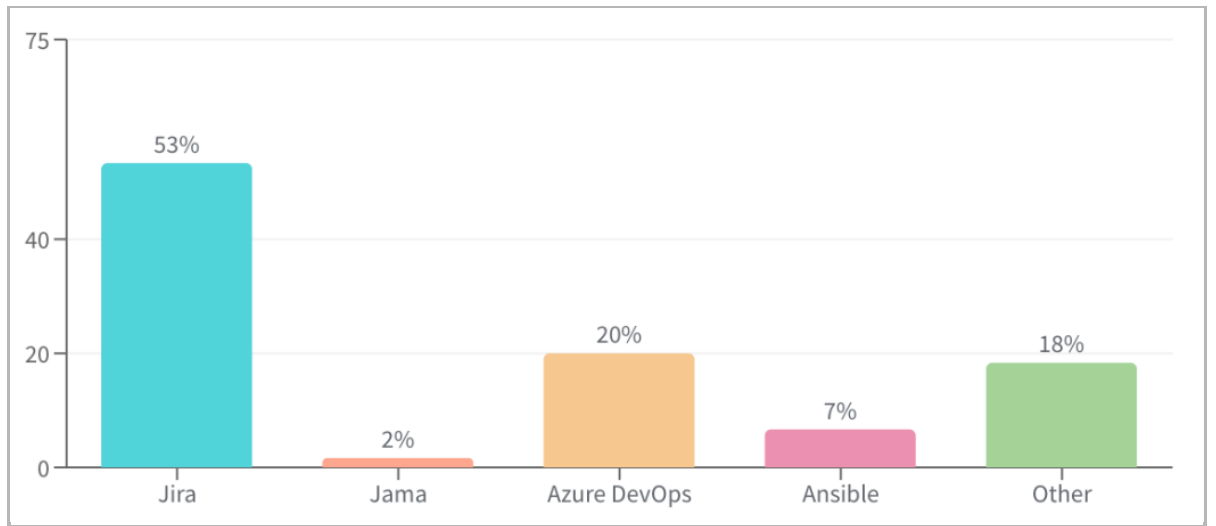

Regarding the participants' feedback about the tools that they are using for software deployment, around (28\%) are using Jenkins, (23\%) are using Azure, around (18\%) are using GitLab, (7\%) are using Atlassian Bamboo, (7\%) are using CodeDeploy, and (13\%) are using other tools as shown in Fig. 24.

Figure 24: Tools used for software deployment

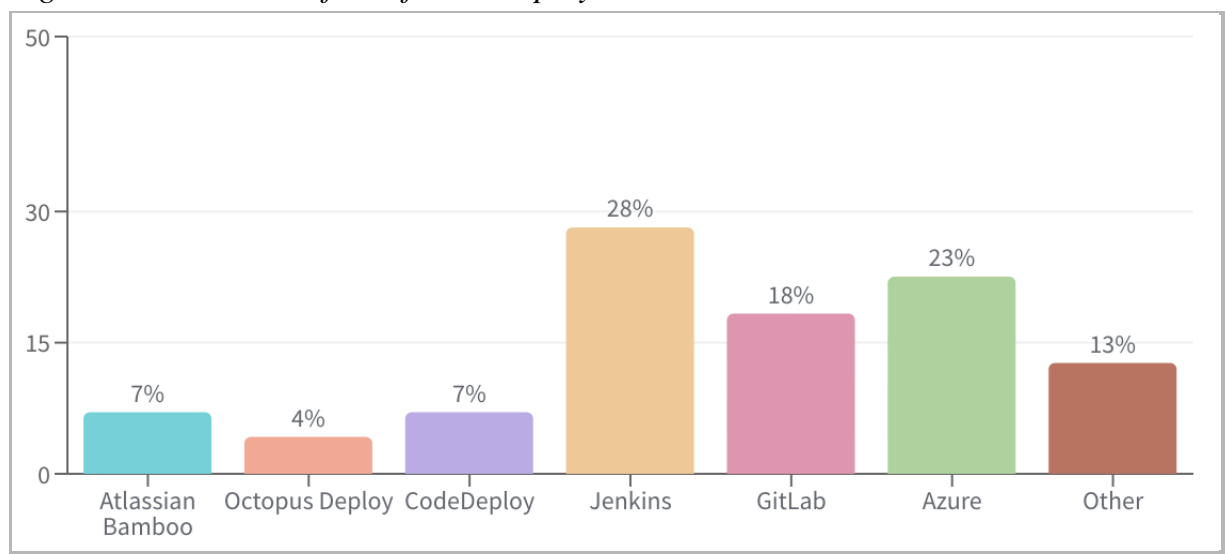

\subsection{Topic 5: Skills improved and gained}

Related to the participants feedback about the skills gained or improved during the pandemic, around (12\%) selected "Being responsible", (12\%) selected "Being self-organized", and (11\%) selected "Commitment to achieve goals". The percentages of the other selected skills varied between $(6 \%)$ and $(9 \%)$ as shown in Fig. 25.

Figure 25: Skills gained and improved during the pandemic 


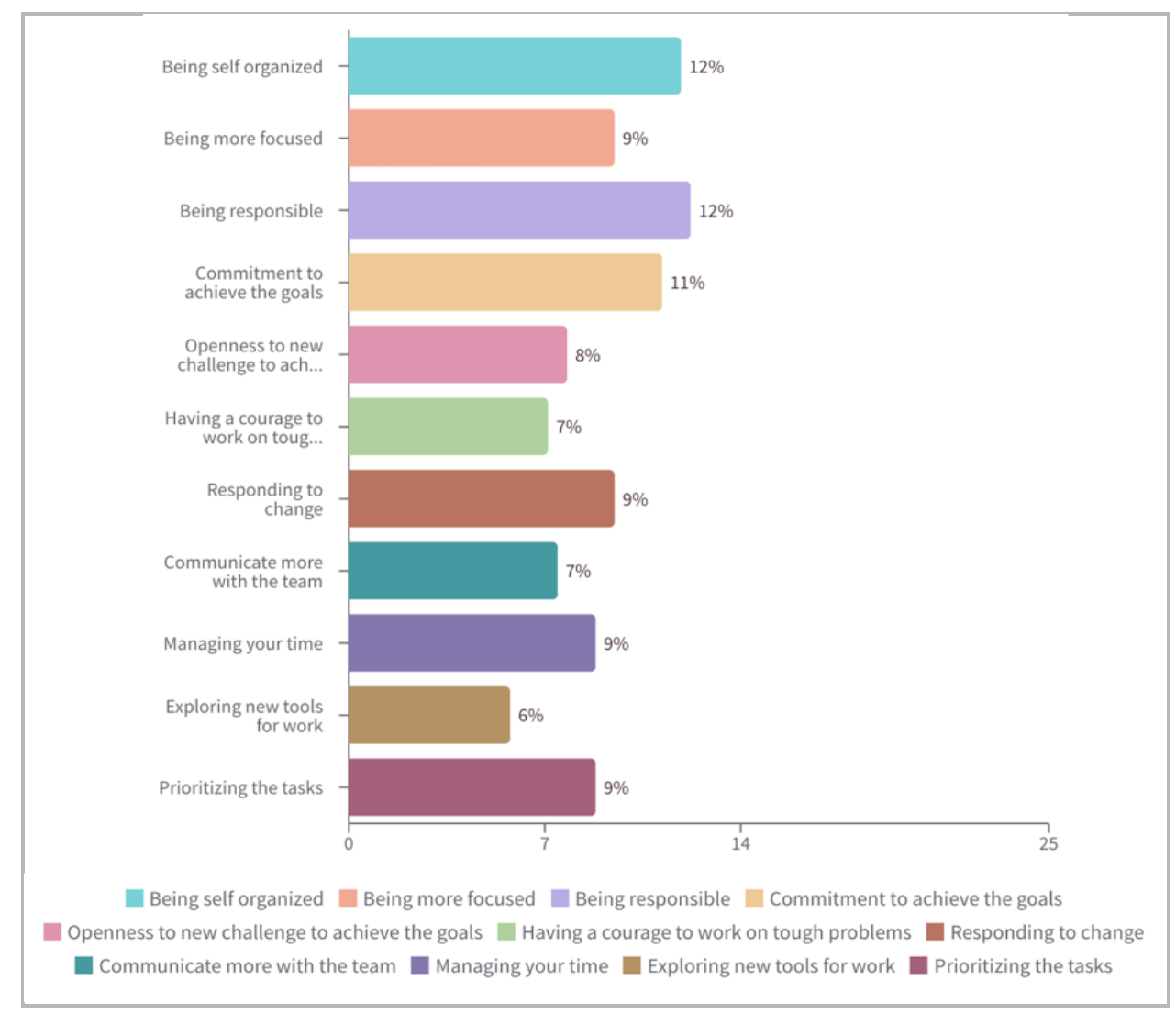

\subsection{Topic 6: Challenges and advantages from participants' points of view}

Regarding participants' feedback about the challenges have been facing during the pandemic, the participants provided several issues which are related to communication, meeting arrangement, time management, working hours, working environment, delivery of the software network issues, and remote access. Some of their answers were: "At first we spent some time arranging ourselves to conduct meetings online instead of physical meetings", "working hours", "Sometimes appointments of meetings", "The limitations in having a face-to-face meeting for scrum events", "Environment to work", "In the beginning there was no remote access authority, "we suffered with paperwork to get the authority", and "We had some difficulties at the testing".

Regarding participants' feedback about the advantages of working Agile online in software development during the pandemic, they provided several advantages which are related to flexibility, efficiency, task management, continuous improvement, finishing the tasks in short time, and saving time. Some of their answers were: "Flexibility", "We seem to get more work done", "Practicing Agile as a distributed team", "Stay safe at home", "Finishing tasks in short period of time", "More focused", "Continuous improvement", and "Prioritizing tasks".

\section{Discussion}

In this study we aimed to examine the impact of COVID-19 pandemic on Agile software development. The general conclusion that can be derived from the literature review and the 
questionnaire results, is that Agile software development did not experience a great impact from the pandemic, neither positively nor negatively.

There are various Agile frameworks that are used by the participants, Scrum was the most used framework by more than three quarters of the participants due to several reasons. Scrum was created for small teams which facilitates good communication, cooperation, self-organization and respond quickly for the rapid changes. Scrum also can be used with the distributed teams.

The new working situation negatively affected the interaction among team members for more than quarter of the participants. This issue can be solved if the companies utilize good communication tools such as Microsoft Teams and Zoom. The same thing is applied for collaboration with and gathering the requirements from customers. However, the findings indicate that more than half of the participants succeeded in reflecting on each other's work in the team for adjustments.

On the other hand, about half of the participants did not face any difficulties concerning the deployment of the code and responding to change whereas only about quarter of the participants faced difficulties. This apparently because of the flexibility and responsiveness of Agile methodology.

More than half of the participants could be self-organizing and got a supportive and motivational environment despite shifting to work remotely. Furthermore, half of the participants maintained the quality of the working software whereas three quarters of the participants continued to deliver the software features as they used before the pandemic. In fact, almost quarter of the participants experienced a positive impact on their working software ranging from huge to moderate to slight. This proved that many teams were able to adapt to work remotely.

In addition, the results showed that some participants got benefits from working at home. They had the opportunity to gain new skills such as being self-organized and responsible, commitment to achieve goals, and managing time.

More than half of the participants are using Jira for software releases and versions management which indicates that this tool is the most popular tool used for software product management in Saudi Arabia. Also, more than half of the participants are using Jenkins as a tool for software deployment because it's an open-source tool providing good services and features for deployment process.

Regarding User Acceptance Test (UAT), less than one third of the participants stated that the UAT did not get affected by the pandemic while a quarter and less than a half their UAT got affected by $50 \%$ and $25 \%$ respectively. This was not unexpected since the pandemic restrictions did not allow the customer to meet with the developing team and try the test personally.

We recognized that because of the Agile methodologies' flexibility, adaptability, resilience, and responsiveness, many software projects adopted these methodologies during the pandemic period, whether they have been utilizing it already or adopting it recently as a result of the pandemic. 


\section{Conclusion and Future Work}

The main objective of this research is to analyze the impact of COVID-19 crisis on Agile software development since there were only few studies in this regard. This study was conducted mostly on Agile software development in Saudi Arabia who are used to implement Agile on their projects or have adopted Agile due to lockdown restrictions. The findings revealed that development teams did not greatly get affected by the new working situation. Including deployment of the code, quality and delivering of the working software, responding to change, maintaining a self-organizing team, and getting a supportive environment. On the other side, the findings showed the percentage of the negative impact on the interactions among team members, the collaboration with and gathering requirements from the customers, and the User Acceptance Test.

Due to time constraints, spreading the questionnaire worldwide was a limitation in this study. The results of the study mostly reflect the experience of Agile software developers in Saudi Arabia. Moreover, the analysis of the study could be more focused, for example based on a specific Agile framework, the age or gender of the participant, or the communication tools being used. This will open new research areas regarding software development and crisis management.

\section{References}

da Camara, R., Marinho, M., Sampaio, S., \& Cadete, S. (2020). How do Agile Software Startups deal with uncertainties by Covid-19 pandemic?. arXiv preprint arXiv:2006.13715.

Ralph, P., Baltes, S., Adisaputri, G., Torkar, R., Kovalenko, V., Kalinowski, M., ... \& Alkadhi, R. (2020). Pandemic programming. Empirical Software Engineering, 25(6), 4927-4961.

Mykytyn, P. P. (2020). COVID-19 and Its Impacts on Managing Information Systems. Information Systems Management, 37(4), 267-271.

Badiale, M. E. (2020). The dynamics of communication in global virtual software development teams: A case study in the agile context during the Covid-19 pandemic.

Marek, K., Wińska, E., \& Dąbrowski, W. (2021). The State of Agile Software Development Teams During the Covid-19 Pandemic. In International Conference on Lean and Agile Software Development (pp. 24-39). Springer, Cham.

Nandwani, G. How To Maintain Team Agility in Covid-19 Era.

Wahbi, A., Raharjo, T., \& Hardian, B. (2020, October). Critical Success Factors in Managing Project Using IS/IT:: Case Study for Projects in Indonesia During COVID-19 Pandemic. In 2020 International Conference on Advanced Computer Science and Information Systems (ICACSIS) (pp. 225-232). IEEE.

Ahmad, M. O., Markkula, J., \& Oivo, M. (2013, September). Kanban in software development: A systematic literature review. In 2013 39th Euromicro conference on software engineering and advanced applications (pp. 9-16). IEEE.

Ghani, I., \& Yasin, I. (2013). Software Security Engineering in Extreme Programming Methodology: A Systematic Literature Review. Science International, 25(2). 


\section{icmets}

$4^{\text {th }}$ International Conference on Modern Research in

ENGINEERING, TECHNOLOGY AND SCIENCE

AMSTERDAM, NETHERLANDS

$16-18$ July 2021

Raišienè, A. G., Rapuano, V., Varkulevičiūtė, K., \& Stachová, K. (2020). Working from Home-Who is Happy? A Survey of Lithuania's employees during the COVID-19 quarantine period. Sustainability, 12(13), 5332.

Bloom, N. (2014). To raise productivity, let more employees work from home. Harvard Business Review, January-February.

Sutherland, J., Viktorov, A., Blount, J., \& Puntikov, N. (2007, January). Distributed scrum: Agile project management with outsourced development teams. In 2007 40th annual Hawaii international conference on system sciences (HICSS'07) (pp. 274a-274a). IEEE.

Paasivaara, M., Durasiewicz, S., \& Lassenius, C. (2009, July). Using scrum in distributed agile development: A multiple case study. In 2009 Fourth IEEE International Conference on Global Software Engineering (pp. 195-204). IEEE.

Stray, V., Moe, N. B., \& Noroozi, M. (2019, May). Slack me if you can! using enterprise social networking tools in virtual agile teams. In 2019 ACM/IEEE 14th International Conference on Global Software Engineering (ICGSE) (pp. 111-121). IEEE.

Ristelä, C. (2020). Possibilities and challenges of virtual agile teams in a nordic organization: case study from insurance industry.

Zelkowitz, M. (2004). Advances in computers: advances in software engineering. Elsevier.

O Connor, M., Conboy, K.,\& Dennehy, D. (2021). COVID-19 affected remote workers: a temporal analysis of information system development during the pandemic. Journal of Decision Systems,1-27.

Sirvastava, N. (2020). Living Agile in COVID Times. Retrieved from https://www.tcs.com/content/dam/tcs/pdf/perspectives/covid-19/Living-Agile-in-CovidTimes-3.pdf 